\title{
Contribuições das técnicas projetivas gráficas para a compreensão da personalidade de andarilhos de estrada
}

\author{
Rodrigo Sanches Peres \\ Universidade de São Paulo - Ribeirão Preto \\ José Sterza Justo \\ Universidade Estadual Paulista - Assis
}

\begin{abstract}
Resumo
Estudos indicam que a deserção que caracteriza o estilo de vida dos andarilhos de estrada é multifatorial e envolve fatores sócio-econômicos e psicológicos. O presente estudo visou investigar as principais características da personalidade de andarilhos de estrada. Para tanto, aplicou-se a Bateria de Grafismos de Hammer em 23 andarilhos albergados em uma instituição assistencial. O material coletado foi avaliado e interpretado em função dos critérios de atribuição de significados fornecidos pela literatura científica especializada. Os dados obtidos indicam que os sujeitos possuem uma imagem corporal comprometida por sentimentos de inferioridade e inadequação e uma organização afetiva marcada por conflitos de ordem sexual, pela utilização de mecanismos de defesa primários e por uma veemente tendência ao isolamento nas relações interpessoais. Tais resultados fornecem subsídios para o delineamento de algumas características de personalidade dos sujeitos estudados. Não obstante, a corroboração das hipóteses em questão depende da realização de novos estudos empíricos.
\end{abstract}

Palavras-chave: andarilhos de estrada; avaliação psicológica; personalidade; técnicas projetivas

\begin{abstract}
Contributions of graphic projective techniques for the understanding of highway wanderers'personality. Research results indicate that the highway wanderers' desertion involves socioeconomic and psychological factors. The objective of the present study was the investigation of the highway wanderers' personality. For so much, the Hammers’ Graphic Battery was applied to a group of 23 highway wanderers sheltered in an caring institution. The collected data was evaluated and interpreted by the utilization of meanings attribution's criteria supplied by the scientific literature. Data analysis indicate that the participants possess a corporal image committed by inferiority feelings and inadequacy and an affective organization marked by sexual conflicts, primary defense mechanisms and a vehement tendency to isolation in interpersonal relationships. Such results supply subsidies for the understanding of some personality characteristics of the researched individuals. However, the corroboration of these hypotheses depends on the accomplishment of new empirical studies.
\end{abstract}

Key-words: highway wanderers; psychological evaluation; personality; projective techniques

\section{Aspectos gerais da errância em andarilhos de estrada}

A presença de andarilhos de estrada, ou trecheiros é cada vez mais freqüente nas rodovias brasileiras. Tais sujeitos vivem caminhando solitariamente pelos acostamentos de auto-estradas e usualmente carregam em um saco ou em uma mochila puída todos os seus pertences. Dentre os diversos tipos de moradores de rua descritos pela literatura científica especializada, os andarilhos de estrada podem ser classificados como outsiders, visto que o termo em questão é utilizado para fazer referência à condição de estar permanentemente e por imputação colocado fora das disposições estruturais de um dado sistema social, ou de estar situacional ou temporariamente excluído, ou de voluntariamente se excluir do comportamento de membros que têm status e função dentro daquele sistema. (Turner, 1974, p. 233)

Cumpre assinalar, contudo, que existem diversos tipos de outsiders. Os andarilhos de estrada se destacam dos demais sujeitos que vivem às margens da sociedade em função do estilo de vida nômade e errante que adotam. Conseqüentemente, a mendicância e o trabalho volante se afiguram como 
os principais meios de subsistência desses indivíduos. Vale salientar também que os andarilhos usualmente se mostram conformados com essa condição, o que pode ser atribuído, em última análise, à falta de perspectivas de retorno às malhas da rede social do mundo contemporâneo. Ademais, ressalte-se que a maioria dos andarilhos consome bebidas alcoólicas de forma constante e abusiva e busca contatos interpessoais apenas em situações de necessidade extrema. Assim sendo, caracterizam-se por um marcante estreitamento da socialidade (Snow \& Anderson, 1998).

A ruptura com os referenciais sociais, emocionais e geográficos que garantem estabilidade e segurança a uma pessoa e a impossibilidade de estabelecer qualquer espécie de vínculo duradouro no trecho torna os andarilhos sujeitos altamente individualizados e alheios a qualquer espécie de coletividade (Castel, 1998). Desse modo, sua sobrevivência geralmente é permeada por um sentimento constante de incerteza, desassistência e isolamento. Não obstante, os andarilhos de estrada podem ser considerados, numa analogia metafórica, uma caricatura do homem da atualidade, visto que a economia globalizada institui o provisório como modo de existência e exige a constante readaptação a novos paradigmas, tornando, assim, cada vez mais efêmeros os relacionamentos afetivos e mais instáveis as fixações sociais (Justo, 1998).

Seguindo essa linha de raciocínio, é possível propor que o imperativo do movimento decorrente da globalização tem implementado um pouco de errância em cada um de nós, visto que a atual realidade social se caracteriza pela compressão do tempo e do espaço, pela "habitação” de espaços de trânsito (ruas, rodoviárias, aeroportos e veículos automotores, dentre outros) e pela dromologia ou, seja, pela lógica fundada na cinergia e na velocidade (Auge, 1994; Bauman, 1999; Virilio, 1996). Conseqüentemente, observase a exaltação da mobilidade como contraponto da estabilidade, do estacionamento e do sedentarismo, de modo que se privilegia o sujeito flexível, desterritorializado e itinerante. Em função disso, não nos permitimos mais ficar parados em um só lugar: estamos constantemente em movimentação, mesmo que sentados defronte à tela de um computador, navegando na internet (Justo, 1998).

\section{Considerações sobre a gênese da deserção}

Abandonar o sedentarismo, abdicar dos referenciais que norteiam a vida no mundo atual e se desertar das fixações sociais, geográficas e afetivas são atitudes drásticas, tendo em vista que inúmeras dificuldades são instaladas com a errância. Em última análise, pode-se considerar que a variedade de injunções que acompanha a itinerância se apresenta como o principal indicador da complexidade do fenômeno da deambulação tal como se apresenta no andarilho. Por isso, parece plausível propor que nenhum evento ou acontecimento isolado, por mais desestruturante que seja, leva, por si só, uma pessoa à condição de nômade errante. Assim sendo, para que se possa compreender a gênese da deserção em suas diversas facetas é preciso considerar a intricada rede de fatores constitutiva desse fenômeno.
A economia globalizada do mundo capitalista contemporâneo leva, em última instância, à precarização das relações de trabalho e ao desemprego, gerando o aumento da vulnerabilidade social, a desfiliação, a pobreza e a exclusão social (Castel, 1998). O desempregado, por não conseguir acompanhar a dinâmica da sociedade salarial e nem tampouco se inscrever nas coerções da atual conjuntura econômica, passa a ser visto como um "inadaptado social”. A falta de um emprego - e a decorrente ausência de reconhecimento social - deflagra experiências de sofrimento, associadas à segregação e à exclusão, levando muitos dos sujeitos submetidos a essas condições a se agregarem aos que vagam pelas ruas, sem teto e sem vínculos sociais estáveis (Singer, 1999).

Conflitos familiares, tanto com os pais no núcleo familiar originário quanto com a esposa e com os filhos, também são fatores preponderantes para a ruptura de um sujeito com o nicho social no qual o mesmo se encontra inserido (Snow \& Anderson, 1998). A ausência de uma família acolhedora, os desentendimentos com os genitores e as desavenças nos relacionamentos conjugais - sobretudo aquelas decorrentes de episódios de infidelidade (Pittman,1994) - são acontecimentos perturbadores que, atuando em conjunto com outras motivações igualmente intensas, podem levar um sujeito a romper com as malhas da rede social estabelecida à sua volta. Assim sendo, a decisão de correr o trecho muitas vezes emerge como uma resposta radical a esses conflitos (Peres, 2001).

Diversos estudos demonstram que o uso abusivo de álcool é um hábito freqüente entre os moradores de rua, uma vez que a embriaguez representa para os sujeitos em questão uma possibilidade de evasão não apenas das condições adversas do presente, mas também das frustrações do passado e da falta de perspectivas para o futuro (Justo, 1998; Snow \& Anderson, 1998; Nascimento \& Justo, 2000). O consumo etílico excessivo, porém, parece estar também intrinsecamente associado à gênese do rompimento com os vínculos estabelecidos na vida sedentária, pois não raro causa conflitos nos relacionamentos interpessoais que culminam com a perda do emprego em decorrência da incapacidade para o trabalho e com o abandono pela família e amigos.

Pesquisas conduzidas com andarilhos de estrada corroboram a aplicabilidade da referida hipótese a essa população, uma vez que os sujeitos em pauta usualmente afirmam que não começaram a ingerir bebidas alcoólicas após a deserção, mas sim intensificaram ainda mais no trecho o consumo etílico que já era freqüente e excessivo no sedentarismo (Nascimento \& Justo, 2000; Peres, 2001). Os andarilhos também reconhecem, em sua maioria, que o uso desmesurado do álcool potencializou as forças cinésicas que os conduziram à itinerância, pois gerou desentendimentos familiares que culminaram com a deserção. Vale destacar ainda que a utilização abusiva do álcool pode ser considerada um dos principais fatores associados à manutenção do desenraizamento, pois inviabiliza a reestruturação ocupacional, social, econômica e afetiva dos andarilhos.

Em vista do exposto, a errância pode ser considerada um fenômeno complexo e multifatorial, impulsionado por uma realidade social que se encontra em contínua transformação 
e, como conseqüência, exige uma readaptação incessante a novos paradigmas. Cumpre assinalar, porém, que não se pode entender os andarilhos de estrada - sobretudo na realidade brasileira - como uma conseqüência direta das tendências dromológicas da modernidade ou das desterritorializações produzidas pela atual substituição dos espaços de confinamento pelos lugares abertos. A errância não é um fenômeno específico da atualidade, visto que a história atesta que a movimentação do homem pelo mundo é um fenômeno tão tipicamente humano que atravessou todos os espaços geográficos e temporais por ele já ocupados.

Não obstante, é preciso considerar que, nos dias de hoje, a compressão do tempo e do espaço atingiu, como assinala Bauman (1999), tal magnitude que possibilita a instantaneidade, ou seja, o alcance imediato das coisas presentes em lugares distintos mediante conexões contínuas entre realidades locais. Enquanto em outras épocas as movimentações humanas eram um meio para se alcançar um lugar novo onde seria possível realizar outro assentamento, no mundo contemporâneo o movimento é um fim, de modo que a vida é comandada por uma constante migração de um lugar a outro. Com isso, os estacionamentos sociais e afetivos se tornam cada vez mais breves, produzindo, como conseqüência, um sujeito cinésico numa sociedade que busca abrandar fronteiras, acelerar o tempo e afrouxar vínculos, filiações, proteções e fixações.

\section{Fatores psicológicos associados ao nomadismo}

Pensar o nomadismo como um fenômeno complexo, multifatorial e impulsionado pelas injunções da atual realidade social parece coerente. Mais especificamente, a influência do desemprego, da pauperização, do alcoolismo e dos conflitos familiares no processo de deserção é igualmente plausível. No entanto, milhões de pessoas atualmente no Brasil e no mundo são acometidas por essas dificuldades e nem por isso todas elas se tornam errantes. É possível propor que isso ocorre porque as condições de vida ganham sentido na medida em que são apreendidas pelo sujeito, pois o mesmo lhes confere significado quando realiza conexões entre os eventos percebidos, compõe figurações de passado, presente e futuro e, como conseqüência, se situa no tempo e no espaço. Tal processo, por sua vez, depende, em última análise, da capacidade do indivíduo de pensar, sentir e simbolizar.

A personalidade do sujeito, ou seja, a unidade individual resultante da interação de fatores biológicos, psicológicos, sociais e culturais que o caracteriza, influencia diretamente a referida capacidade, de modo que se afigura como uma variável determinante para a elaboração das condições objetivas de vida e para o delineamento dos padrões de comportamento a serem adotados. É possível considerar, portanto, que a personalidade do sujeito influencia a percepção da realidade externa, permite o vislumbramento de suas possibilidades de ação e direciona, em última análise, sua trajetória de vida. Nesse sentido, pode fazer com que as dificuldades comuns a um grande número de indivíduos sejam percebidas por algumas pessoas como algo tão sofrível a ponto de impulsionálas para o mundo de incertezas e privações da vida nômade.
Recentemente alguns estudos têm sido realizados com andarilhos de estrada, enfatizando as condições de vida dessa população no cenário psicossocial da contemporaneidade (Justo, 1998; Justo, 2000; Nascimento \& Justo, 2000; Peres, 2001; Snow \& Anderson, 1998). Embora tais estudos tenham produzido um conhecimento razoável sobre a vida errante, pouco se sabe sobre a constituição psicológica desses sujeitos. Faz-se necessário dedicar maior atenção a essa questão para que se avance na compreensão desse complexo fenômeno e, desse modo, se possa aprimorar as estratégias de intervenção voltadas a essa população, visto que as políticas públicas adotadas com o intuito de reinserir socialmente sujeitos marginalizados não levam em conta a heterogeneidade dos “excluídos", e assim, não têm alcançado resultados efetivos (Castel, 1998).

O presente estudo, portanto, possui como objetivo investigar aspectos da personalidade de andarilhos de estrada, focalizando mais especificamente: as principais manifestações e características, a qualidade de expressão gráfica e organização perceptual e conteúdos referentes à associação de estímulos.

\section{Método}

\section{Participantes}

O presente estudo contou com a participação de 23 andarilhos de estrada do gênero masculino. A faixa etária dos mesmos variou de 19 a 63 anos (média de 39,7 anos) e o tempo no trecho oscilou de 6 meses a 18 anos (média de 6,2 anos). A inclusão dos participantes na amostra foi direcionada em função de alguns critérios, a saber: (a) encontrar-se temporária e espontaneamente hospedado no Albergue Noturno São Vicente de Paula ${ }^{1}$, na cidade de São Carlos, SP; (b) assumir a condição de nômade errante, isto é, reconhecer que há pelo menos seis meses se encontra sem residência e emprego fixos e que corre o trecho, ou seja, peregrina pelas vias de transporte terrestre do país; (c) concordar espontaneamente em participar do estudo, (d) possuir mais de 18 anos de idade; e (e) não apresentar sinais de embriaguez, tais como incoerência verbal, falta de equilíbrio e tremores.

\section{Desenho metodológico}

Optou-se por adotar no presente estudo um enfoque idiográfico, descritivo, exploratório, qualitativo e interpretativo considerando-se que esse desenho metodológico seria adequado frente aos objetivos propostos e, assim, forneceria elementos para a compreensão de alguns dos principais aspectos da personalidade dos indivíduos pesquisados.

\section{Instrumentos}

É consenso entre os pesquisadores que se dedicam à investigação da personalidade que nenhuma técnica isolada pode oferecer, por si só, um panorama profundo acerca do psiquismo de um indivíduo, pois, em última análise, certas limitações e restrições são inerentes aos instrumentos psicológicos. Desse modo, a combinação de diferentes técnicas é 
considerada o procedimento mais adequado para que seja possível uma avaliação psicológica confiável, visto que o processo de comparação dos dados coletados a partir da utilização de um determinado recurso com as informações coligidas mediante o emprego de outros instrumentos permite que o pesquisador possa corroborar ou refutar com maior segurança suas hipóteses (Cunha, 2000a).

Diante do exposto, adotou-se como instrumento no presente estudo a Bateria de Grafismos de Hammer. Trata-se, na realidade, não de um instrumento propriamente dito, mas sim da combinação de três técnicas projetivas gráficas: o Desenho da Figura Humana (DFH) de Machover, o HouseTree-Person (HTP) de Buck e o Desenho da Família (DF) de Corman. Assim sendo, a execução da Bateria de Grafismos de Hammer consiste na realização de cinco desenhos: uma casa, uma árvore, uma figura humana, uma figura humana do sexo oposto ao da primeira e uma família. O participante utiliza uma folha de papel em branco para executar cada uma das produções e tem à disposição para tanto um lápis preto e uma borracha. Após finalizar os desenhos, solicita-se ao sujeito que responda a um questionário padronizado composto por perguntas relativas a determinados aspectos de cada uma das figuras.

Vale destacar que as técnicas projetivas pareceram adequadas frente aos objetivos do presente estudo levando-se em conta que os instrumentos deste tipo possibilitam uma exploração da personalidade mais global e livre do que se pode obter mediante o emprego de outros métodos, uma vez que a execução da tarefa proposta implica em um intenso grau de criação e elaboração pessoal. Cumpre assinalar, por fim, que se optou por utilizar exclusivamente técnicas gráficas tendo em vista que, de acordo com Campos (1969/1998), os instrumentos desse tipo podem ser perfeitamente aplicados em sujeitos com baixo nível educacional, portadores de dificuldades de expressão verbal ou excessivamente retraídos, como é o caso da maioria dos andarilhos de estrada. Ademais, as técnicas projetivas gráficas favorecem a projeção de conteúdos inconscientes, dificultam o emprego de defesas estereotipadas, possuem elevada sensibilidade e agudeza clínica e são de aplicação fácil e rápida (Arzeno, 1995; Hammer, 1969/1981, Lourenção van Kolck, 1984).

\section{Técnica de coleta dos dados}

Antes de iniciar a coleta dos dados, estabeleceu-se individualmente o rapport com cada um dos indivíduos elegíveis para o presente estudo, fornecendo-lhes, de modo simples e compreensível, as informações e os esclarecimentos pertinentes acerca dos objetivos e procedimentos da presente pesquisa. Os que concordaram espontaneamente em participar da pesquisa foram encaminhados então a uma sala reservada e com condições adequadas nas dependências da instituição onde estavam albergados. Nessa sala foi então aplicada, em uma única sessão, a Bateria de Grafismos de Hammer. As recomendações éticas e técnicas preconizadas pela literatura especializada foram adotadas como referencial para a coleta dos desenhos.
Dessa forma, as instruções apresentadas aos indivíduos avaliados foram, em linhas gerais, as seguintes: "Por favor, desenhe uma casa"; "Por favor, desenhe uma árvore”; "Por favor, desenhe uma figura humana”; "Por favor, desenhe uma figura humana do sexo oposto ao daquela que você acabou de desenhar"; "Por favor, desenhe uma família”. As folhas de papel foram entregues aos sujeitos na posição horizontal para o desenho da casa, vertical para o desenho da árvore e das figuras humanas e novamente horizontal para o desenho da família. Ressalte-se ainda que se adotou como norma aceitar os desenhos incompletos e estereotipados, uma vez que a ocorrência de produções com tais características pode indicar a existência de conflitos severos relacionados à área negligenciada e seus significados simbólicos (Hammer, 1969/1981).

\section{Técnica de análise dos dados}

A maior parte dos pesquisadores que emprega técnicas projetivas gráficas como instrumento de investigação psicológica prioriza um exame essencialmente intuitivo com parâmetros internacionalmente referendados dos desenhos. Não obstante, considerou-se relevante submeter o material coletado a uma avaliação mais sistemática. Para tanto, foi elaborado especialmente para o presente estudo um protocolo de avaliação composto por 126 indicadores ${ }^{2}$ (sendo 23 deles referentes ao desenho da casa, 25 referentes ao desenho da árvore, 46 referentes ao desenho das figuras humanas e 32 referentes ao desenho da família), relacionados aos aspectos gerais, formais e de conteúdo dos desenhos. Assim sendo, as produções coligidas foram inicialmente avaliadas mediante o emprego do referido protocolo.

Ressalte-se, porém, que os desenhos também foram submetidos a uma análise qualitativa e interpretativa, pois a maioria dos pesquisadores responsáveis pelos avanços das técnicas projetivas gráficas considera esta estratégia de avaliação mais reveladora - ainda que menos objetiva - do que o exame quantitativo (Arzeno, 1995; Grassano; 1996). Devido à inexistência de pesquisas voltadas à padronização da Bateria de Grafismos de Hammer para adultos brasileiros, as interpretações foram baseadas nos mesmos estudos que forneceram as diretrizes para a elaboração do protocolo de avaliação. Vale destacar, entretanto, que alguns desses estudos, além de terem sido conduzidos há décadas com indivíduos norteamericanos, não apresentam um sistema ordenado de análise dos desenhos. De qualquer forma, mostram-se de grande relevância, pois subsidiam a atribuição de significados a diversos aspectos das produções gráficas.

Vale destacar ainda que, com o intuito de conferir maior fidedignidade às interpretações, se levou em consideração a convergência dos indícios verificados nos diferentes desenhos e, conseqüentemente, foi executada uma avaliação global do conjunto das produções coletadas. Tal procedimento é extremamente importante para a adequada análise do material coligido mediante o emprego de técnicas projetivas gráficas, tendo em vista que um único aspecto de uma figura jamais possui, por si só, um significado específico e nem 
tampouco reflete necessariamente traços da personalidade do participante que a produziu. Como aponta a literatura científica especializada, as características de um desenho são influenciadas não apenas por fatores psicológicos, mas também por variáveis sociais e culturais (Lourenção van Kolck, 1984; Souza, 2000). Ademais, as informações oriundas de outros estudos conduzidos com andarilhos de estrada - tais como as pesquisas de Justo (1998; 2000), Nascimento e Justo (2000) e Peres (2001; 2002a; 2002b) - também foram utilizadas para nortear a interpretação do material coligido.

\section{Resultados e discussão}

A avaliação dos aspectos gerais dos desenhos revela que parte das produções coletadas (14 desenhos da casa, 10 desenhos da família e 9 desenhos da árvore e das figuras humanas) se localiza na parte superior da folha de papel. Segundo Hammer (1969/1981) e Lourenção van Kolck (1984), tal indício geralmente reflete um distanciamento do mundo exterior e um excessivo apego à fantasia. Além disso, outra parcela das produções coletadas (12 desenhos da casa, 10 desenhos da árvore e das figuras humanas e 9 desenhos da família) é de tamanho pequeno, o que pode estar associado a sentimentos depreciativos e tendências ao retraimento (Machover, 1949/1962; Levy, 1967; Cunha, 2000b). Tais hipóteses tornam-se mais consistentes tendo em vista que outras pesquisas também apontam que andarilhos de estrada não raro mantêm um frágil vínculo com a realidade, evitam contatos interpessoais na maioria das circunstâncias e se sentem usualmente inferiores e inadequados em comparação com indivíduos que adotam o sedentarismo como estilo de vida (Justo, 2000; Peres, 2001).

Cumpre assinalar também que oito participantes se recusaram a executar a segunda figura humana e outros dois a desenhar a família. Além disso, onze andarilhos inicialmente se negaram a produzir o desenho da família, mas acabaram consentindo com a tarefa após ter-lhes sido novamente assegurado, assim como havia sido feito no início da coleta de dados, que suas habilidades artísticas não estavam sendo avaliadas. Faz-se necessário destacar ainda que o desenho da família de dois sujeitos e o desenho da figura humana de outros sete indivíduos não foram devidamente finalizados. De acordo com a literatura científica especializada, a ocorrência de tais comportamentos leva à hipótese de situações semelhantes a resistências, um indício de insegurança dos sujeitos em relação às suas próprias capacidades de interação com o meio (Machover, 1949/1962; Portuondo, 1973; Retondo, 2000). Não obstante, é preciso reconhecer que as resistências apresentadas possivelmente também podem estar associadas, em algum grau, à pouca familiaridade dos sujeitos com a tarefa proposta, e ou ao uso de materiais gráficos.

Em relação aos aspectos formais das produções, vale destacar que na maior parte do material coletado se verificou escassez ou até mesmo ausência de detalhes (18 desenhos da família, 14 desenhos da árvore, 13 desenhos das figuras humanas e 12 desenhos da casa) e complementos (20 dese- nhos das figuras humanas, 19 desenhos da família e 13 desenhos da casa e da árvore). Segundo Hammer (1964/1991), tais ocorrências podem representar indícios de tendência ao retraimento e baixa energia vital, ou mesmo podem ser consideradas um subproduto da baixa escolaridade dos sujeitos (Souza, 2000). Além disso, os personagens de 18 desenhos da família e de 17 figuras humanas apresentam uma simetria inadequada, o que revela, indicadores, segundo Corman (1967), Arzeno (1995) e Retondo (2000), de traços de insegurança e desequilíbrio emocional.

No que se refere aos aspectos de conteúdo do desenho da casa, faz-se necessário destacar que as produções gráficas de 17 participantes apresentam alguma espécie de desordem referente aos contornos da parede: oito delas foram executadas mediante o emprego de traços excessivamente reforçados, cinco se mostram inadequadamente integradas e quatro apresentam linhas frágeis e pouco vigorosas. As referidas características sugerem que os sujeitos em questão vêm sendo acometidos por um sentimento de colapso emocional em virtude de uma iminente desintegração do ego (Buck, 1970/ 2003; Cunha, 2000b; Hammer, 1969/1981). Cumpre assinalar que os resultados de outros estudos conduzidos com essa população parecem corroborar tal hipótese, pois apontam que andarilhos de estrada usualmente apresentam uma estrutura egoica pouco consistente e se caracterizam por um acentuado desequilíbrio emocional (Justo, 2000).

O desenho da porta da casa dos sujeitos pesquisados também merece destaque, uma vez que três deles produziram tal detalhe em tamanho pequeno, dois com acentuados reforços e outros três em localização pouco usual (acima da linha do solo e sem degraus). Ademais, a porta foi omitida em outros três desenhos. Em linhas gerais, essas características denotam que os indivíduos em questão podem ter dificuldades severas nos relacionamentos interpessoais e tendem ao isolamento - motivados possivelmente por sentimentos de inadequação - ou quando permitem algum contato o fazem com muitas restrições e desconfianças (Buck, 1970/2003; Hammer, 1969/1981). Tais hipóteses ganham maior sustentação ainda tendo em vista que cinco participantes reforçaram os contornos das janelas, cinco desenharam janelas acima da linha superior da porta e outros quatro omitiram esta parte da casa de suas produções (Campos, 1969/1998; Retondo, 2000).

Ressalte-se também que outros estudos indicam que a solidão se afigura como uma das principais características dos andarilhos de estrada (Justo, 2000; Nascimento \& Justo, 2000; Peres, 2001), o que parece referendar a pertinência das proposições precedentes. Faz-se necessário destacar ainda que, como aponta Justo (1998), o isolamento é visto pelos andarilhos como uma condição de sobrevivência na estrada, pois os mesmos referem que é mais fácil obter ajuda estando sozinhos do que acompanhados. Nesse sentido, parece coerente supor que o retraimento da sociabilidade, além de fomentar e incrementar a errância, se acentua mediante a vivência das injunções inerentes ao nomadismo. Conseqüentemente, pode ser considerado o resultado não apenas de eventos ocorridos em estágios anteriores do desenvolvimen- 
to, mas também da condição na qual os andarilhos de estrada se encontram na atualidade.

A análise dos aspectos de conteúdo do desenho da árvore indica que treze produções apresentam uma relação tronco-copa inadequada. A maioria destes desenhos possuía um tronco excessivamente destacado, em detrimento de uma copa pouco significativa, o que pode revelar um indício de contatos inadequados com a realidade e "refúgio" com uso de fantasia (Lourenção Van Kolck, 1984; Retondo, 2000). Além disso, em 12 desenhos da árvore se nota que o tronco é constituído por duas linhas retas traçadas desde a base até o topo, o que pode ser entendido como descritor de características associadas a infantilidade e imaturidade. Além disso, foi possível verificar a presença de nódulos e rachaduras no tronco de 11 desenhos da árvore. Considerando suas formas e contornos, tais elementos podem estar associados não a um simples adereço do desenho, mas sim à expressão gráfica de situações ligadas a traumas psíquicos (Buck, 1970/2003; Campos, 1969/1998; Hammer, 1969/1981; Koch, 1968).

A característica de infantilidade observada e sugerida pela análise dos desenhos da árvore coligidos poderia ser compreendida, segundo a psicologia dinâmica, como uma faceta da expressão de primitivismo que caracteriza a vida dos andarilhos. De certa maneira, pensamos que os mesmos retornam a uma situação semelhante à da infância no que diz respeito à extrema dependência do outro para a satisfação das necessidades mais elementares (abrigo, descanso e alimentação). No entanto, é preciso caracterizar tal hipótese levando-se em consideração que o enfrentamento das adversidades da vida "no trecho" nem sempre envolve a busca de auxílio junto à figura protetora das instituições filantrópicas ou assistenciais e, assim, exige o emprego de recursos adaptativos mais complexos. Nesse sentido, no estado atual do conhecimento sobre a personalidade dos andarilhos de estrada, a cautela recomenda considerar, por um lado, a existência de tendências à regressão no plano psicológico, mas também a presença, por outro lado, de dispositivos adaptativos capazes de prover respostas elaboradas a ponto de garantir a sobrevivência em meio a uma situação de vida desafiadora.

A análise dos aspectos de conteúdo dos desenhos das figuras humanas revela que uma parcela considerável dos participantes produziu figuras com características particulares, tais como cabeças grandes (16 sujeitos), traços faciais demasiadamente simplificados (17 sujeitos), olhos sem pupilas (9 sujeitos) ou fechados (3 sujeitos), narinas acentuadas (5 sujeitos), boca entreaberta (12 sujeitos) e pescoço fino e comprido (10 sujeitos). Em linhas gerais, tais indicadores podem se caracterizar como expressão de situações conflitivas no contato com o mundo exterior e de dificuldades relativas ao controle dos impulsos, imaturidade, dependência, egocentrismo, passividade e tendência à evasão da realidade (Levy, 1967; Lourenção van Kolck, 1984; Machover, 1949/ 1962; Retondo, 2000).

Tais hipóteses são reforçadas levando-se em conta que nove andarilhos de estrada não desenharam o tronco das figuras humanas e dez omitiram braços e pernas - elementos que os autores simbolizam como sendo da estabilidade emocional do sujeito e seu contato com o mundo à sua volta (Portuondo, 1973). Vale destacar, por fim, que um número considerável de sujeitos desenhou figuras humanas com nariz pontiagudo (9 sujeitos), cabelos escassos e desordenados (11 sujeitos) sem diferenciar adequadamente as figuras masculina e feminina (16 sujeitos), o que, segundo Campos (1969/1998), pode estar associado a conflitos de características sexual.

Em relação aos aspectos de conteúdo do desenho da família, observou-se que 13 andarilhos de estrada produziram figuras razoavelmente próximas umas das outras. Partindo do pressuposto de que a distância entre as figuras no desenho da família se destaca, segundo Corman (1967), como um indicador na verificação da qualidade dos relacionamentos familiares, poder-se-ia considerar tal ocorrência um indicador da existência de integração nas trocas afetivas entre os sujeitos e seus entes. Não obstante, muitos andarilhos referem que adotaram o nomadismo como estilo de vida justamente em função de desentendimentos, conflitos e desavenças que tornaram insuportável o cotidiano no seio da família. Assim sendo, entendemos que a proximidade das figuras nos desenhos em questão pode ser analisada como uma tentativa de forjar simbolicamente uma proximidade familiar que é inexistente na realidade.

Vale destacar também que a análise global da maioria dos desenhos não transmite uma impressão de integração e, assim, reforça a hipótese precedente, pois, apesar de próximas umas das outras, as figuras que constituem as famílias paradoxalmente parecem distantes e até mesmo isoladas em alguns casos, considerando-se a postura, a disposição espacial dos personagens e o posicionamento de seus braços (quando presentes). Tais indícios sugerem que não há comprometimento emocional significativo entre os sujeitos que produziram este tipo de desenho e seus familiares (Freitas \& Cunha, 2000b; Piccolo, 1981), muito embora não tenha sido investigada esta questão na presente pesquisa. Acrescentese ainda o fato de que os desenhos da família coletados são consideravelmente empobrecidos e as figuras inadequadamente integradas, o que leva a pensar na hipótese de que os sujeitos pesquisados se sentem desvalorizados pela família e vice-versa. (Corman, 1967; Levy, 1967; Lourenção van Kolck, 1984; Portuondo, 1973).

Entretanto, é preciso reconhecer que alguns andarilhos, a despeito das condições em que vivem, procuram preservar o contato com a família, chegando até mesmo a fazer visitas periódicas a seus entes. Possivelmente isso ocorre porque a vida no trecho concorre para a ressignificação das vivências afetivas decorrentes dos relacionamentos familiares. Como conseqüência desse fenômeno, mesmo entre os sujeitos marcados pela ocorrência de grandes desavenças familiares na vida sedentária não se notam indícios de ódio e rancor em relação a seus entes, mas sim apenas de mágoa e pesar. Em contrapartida, algumas exceções podem ser observadas nos casos em que o principal motivo dos conflitos familiares é 
atribuído à infidelidade conjugal da mulher. De qualquer forma, o abismo criado entre o passado sedentário e o presente nômade parece neutralizar as cargas emocionais dos registros de experiências anteriores.

\section{Considerações finais}

Faz-se necessário reconhecer que, por uma série de razões, os resultados obtidos não possuem um caráter definidor para a análise e avaliação da personalidade em definitivo. Em primeiro lugar, o número de participantes é reduzido, pois o contato com andarilhos de estrada é extremamente custoso. Em segundo lugar, por esta mesma razão, não foi possível combinar outros instrumentos com a Bateria de Grafismos de Hammer, o que possivelmente conferiria maior fidedignidade às interpretações elaboradas. Em terceiro lugar, não se encontrou na literatura científica nenhum estudo voltado especificamente à investigação da personalidade dos sujeitos em questão, o que dificultou o processo de comparação dos dados obtidos. Em quarto lugar, por fim, não existem normas para avaliação da Bateria de Grafismos de Hammer em populações brasileiras, o que torna limitadas as interpretações formuladas a partir do emprego do referido instrumento, especificamente neste caso. Desse modo, o presente estudo efetivamente se afigura como uma pesquisa piloto de caráter observacional do fenômeno.

A despeito dessas limitações, os resultados obtidos possibilitam o delineamento inicial na identificação de algumas características de personalidade que podem estar intimamente associadas à vida nômade dos andarilhos de estrada. Não se trata de defender a existência de um tipo de personalidade inerente aos sujeitos em questão, mas sim de tentar compreender como certos modos de perceber, sentir, pensar e agir são operacionalizados na itinerância, produzindo o suporte psicológico necessário para sustentar o indivíduo nessa condição e capacitá-lo para um tipo de vida cujas exigências são muito diferentes daquelas existentes no sedentarismo. Evidencia-se, assim, que o presente estudo está voltado para a compreensão das diversas características e exigências da errância no plano psicológico, dentro de uma perspectiva psicossocial.

Cumpre assinalar também que se deve tomar com cautela as interpretações oriundas da análise dos desenhos coligidos tendo em vista que avaliar sob a ótica sedentarista a personalidade de indivíduos que - assim como os andarilhos de estrada - vivem alheios ao modelo da estabilidade engendra uma leitura falaciosa da errância. Assim sendo, as características observadas dos sujeitos pesquisados foram consideradas em função dos arranjos que os mesmos operacionalizam com as condições de vida inerentes ao trecho. Nesse sentido, variáveis como a tendência ao retraimento que, de acordo com os resultados obtidos, é comum, em maior ou menor grau, aos participantes do presente estudo, não se afigura, por si só, como uma característica patológica ou desadaptativa e nem tampouco deve ser tomada com um indício de sofrimento psíquico, mas sim como uma proteção frente a uma realidade hostil.
Por fim, faz-se necessário uma última reflexão acerca da aproximação entre a personalidade dos andarilhos de estrada e os modelos de subjetivação emergentes na contemporaneidade. Os resultados do presente estudo sugerem que a personalidade dos indivíduos avaliados se constitui e funciona à feição da personalidade do sujeito contemporâneo, expressando não um desvio ou um sintoma individual, mas as pressões da atualidade e os sintomas desse tempo. Dessa forma, ao invés de se tomar os andarilhos de estrada como “excluídos”, parece mais proveitoso visualizar em sua condição de vida o impacto radical das forças dromológicas que atuam na contemporaneidade, impelindonos a desenvolver formas de convivência com compressões do espaço e do tempo cada vez maiores.

Ainda que guardadas as devidas proporções, a errância dos andarilhos de estrada denota a presença na sociedade atual de uma ética mais fundada no nomadismo do que no sedentarismo. Não é absurdo vislumbrar, ainda que apenas como mero exercício de reflexão ou como tentativa de delineamento de novos caminhos para pesquisas futuras, que a situação de isolamento, a rarefação dos relacionamentos afetivos, a movimentação constante, a desterritorialização, a insegurança, a provisoriedade, a habitação de espaços abertos e tantas outras situações vividas de forma radical pelos andarilhos estejam conectadas com as mesmas forças dromológicas que estão produzindo o abrandamento dos vínculos trabalhistas, a abreviação das relações interpessoais, a busca de emprego em regiões cada vez mais longínquas, a utilização de lugares de trânsito como espaços de convivência ou mesmo moradia, a impregnação da noção de provisoriedade e acaso no cotidiano e assim por diante. Não se trata, evidentemente, de igualar situações distintas, mas apenas de apontar um caminho para a elaboração de uma lógica comum em diferentes formas de vivência do movimento.

\section{Agradecimentos}

Os autores agradecem o subsídio da Fundação de Amparo à Pesquisa do Estado de São Paulo (FAPESP) e também a colaboração de Lucinéia Francisco Batistela, professora do Departamento de Psicologia Clínica da Universidade Estadual Paulista (Faculdade de Ciências e Letras de Assis).

\section{Referências}

Arzeno, M. E. G. (1995). Psicodiagnóstico clínico (B. A. Neves, Trad.). Porto Alegre: Artes Médicas.

Augé, M. (1994). Não-lugares: introdução a uma antropologia da supermodernidade. Campinas: Papirus.

Bauman, Z. (1999). Globalização: as conseqüências humanas. Rio de Janeiro: Jorge Zahar.

Buck, J. N. (2003). H-T-P: manual e guia de interpretação (R. C. Tardivo, Trad.). São Paulo: Vetor. (Original publicado em 1970)

Campos, D. M. S. (1998). O teste do desenho como instrumento de diagnóstico da personalidade. Petrópolis: Vozes (Original publicado em 1969)

Castel, R. (1998). As metamorfoses da questão social: uma crônica do salário (I. D. Poletti, Trad.). Petrópolis: Vozes. 
Corman, L. (1967). El test del dibujo de la familia en la práctica médicopedagógica (I. C. Ibañez, Trad.) Buenos Aires: Kapelusz.

Cunha, J. A. (2000a). Estratégias de avaliação: perspectivas em psicologia clínica. In J. A. Cunha (Org.), Psicodiagnóstico-V (pp. 19-22). Porto Alegre: Artes Médicas.

Cunha, J. A. (2000b). Técnicas projetivas gráficas: por que sim? por que não? São Paulo: Casa do Psicólogo.

Freitas, N. K., \& Cunha J. A. (2000a). Desenho da casa, árvore e pessoa (HTP). In J. A. Cunha (Org.), Psicodiagnóstico-V (pp. 519-527). Porto Alegre: Artes Médicas.

Freitas, N. K., \& Cunha J. A. (2000b). Desenho da família. In J. A. Cunha (Org.), Psicodiagnóstico-V (pp. 513-518). Porto Alegre: Artes Médicas.

Grassano, E. (1996). Indicadores psicopatológicos nas técnicas projetivas (L. S. P. C. Tardivo, Trad.). São Paulo: Casa do Psicólogo.

Hammer, E. F. (1981). A técnica projetiva da casa-árvore-pessoa: interpretação de conteúdo (E. Nick, Trad.). In E. F. Hammer (Org.), Aplicações clínicas dos desenhos projetivos (pp.121-153). Rio de Janeiro: Interamericana. (Original publicado em 1969)

Hammer, E. F. (1991). The House-Tree-Person (HTP) clinical research manual. Los Angeles: Western Psychological Services. (Original publicado em 1964)

Justo, J. S. (1998). Errância e errantes: um estudo sobre os andarilhos de estrada. In J. S. Justo \& R. Y. Sagawa (Orgs.), Rumos do saber psicológico (pp.125139). São Paulo: Arte \& Ciência.

Justo, J. S. (2000). Saúde mental em trânsito: loucura e a condição de itinerância na sociedade contemporânea. In M. L. Boarini (Org.), Desafios na atenção à saúde mental (pp. 9-30). Maringá: EDUEM.

Koch, K. (1968). O teste da árvore (O. Mantovani, Trad.). São Paulo: Mestre Jou.

Levy, S. (1967). El dibujo de la figura humana como test proyectivo. In L. E. Abt \& L. Bellak (Orgs.), Psicologia proyectiva (pp. 156-176). Buenos Aires: Paidós.

Loureiro, S. R., \& Romaro, R. A. (1987). Caracterização da função lógica a partir dos índices detectados através da Bateria de Grafismos de Hammer. Psicologia: Teoria e Pesquisa, 2(3), 117-123.
Lourenção van Kolck, O. (1984). Técnicas projetivas gráficas no diagnóstico psicológico. São Paulo: EPU.

Machover, K. (1962). Proyeccion de la personalidad en el dibujo de la figura humana (J. M. Gutierrez, Trad.). Havana: Cultural. (Original publicado em 1949)

Nascimento, E. C., \& Justo, J. S. (2000). Vidas errantes e alcoolismo: uma questão social. Psicologia: Reflexão e Crítica, 13(3), 529-538.

Pitman, D. (1994). Mentiras privadas: a infidelidade e a traição da intimidade (M. A. Veronese, Trad.). Porto Alegre: Artes Médicas.

Peres, R. S. (2001). Andarilhos de estrada: estudo das motivações e da vivência das injunções características da errância. Psico-USF, 6(1), 67-75.

Peres, R. S. (2002a). O desenho da figura humana de Machover aplicado em andarilhos de estrada. Psicologia: Teoria e Prática, 4(1), 81-92.

Peres, R. S. (2002b). Tão longe, tão perto: andarilhos de estrada e a vivência do distanciamento familiar. Psicologia, 3(2), 6-13.

Piccolo, E. G. (1981). Defesas nos testes gráficos (M. Felzenszwalb, Trad.). In M. L. S. Ocampo, M. E. G. Arzeno, \& E. G. Piccolo (Orgs.), O processo psicodiagnóstico e as técnicas projetivas (pp. 205-311). São Paulo: Martins Fontes.

Portuondo, J. (1973). Test proyectivo de Karen Machover. Madri: Biblioteca Nueva.

Retondo, M. F. N. G. (2000). Manual prático de avaliação do HTP (casaárvore-pessoa) e família. São Paulo: Casa do Psicólogo.

Singer, P. (1999). Globalização e desemprego: diagnóstico e alternativas. São Paulo: Contexto.

Snow, D., \& Anderson, L. (1998). Desafortunados: um estudo sobre o povo da rua (S. Vasconcelos, Trad.). Petrópolis: Vozes.

Souza, A. M. D. R. (2000). Implicação do fator cultural regional nos desenhos da figura humana (DFH) produzidos por sujeitos adultos: análise da diferenciação sexual e de aspectos projetivos. Tese de doutorado nãopublicada, Universidade de São Paulo, São Paulo.

Turner, V. (1974). Dramas, fields and metaphors: symbolic action in human society. Ithaca: Cornell University Press.

Virilio, P. (1996). Velocidade e política. São Paulo: Estação Liberdade.

1. Trata-se de uma instituição assistencial - mantida pela Prefeitura Municipal e por uma instituição religiosa que oferece refeição, pernoite e passes de ônibus à população economicamente desfavorecida.

2. Tais indicadores foram inspirados nas proposições da literatura científica especializada (Machover, 1949/ 1962; Corman, 1967; Levy, 1967; Koch, 1968; Portuondo, 1973; Hammer, 1969/1981; Piccolo, 1981; Lourenção van Kolck, 1984; Loureiro \& Romaro, 1987; Hammer, 1964/1991; Arzeno, 1995; Grassano; 1996; Campos, 1969/1998; Cunha, 2000b; Freitas \& Cunha, 2000a; Freitas \& Cunha, 2000b; Retondo, 2000; Buck, 1970/2003).

Rodrigo Sanches Peres é mestre em Psicologia pela Universidade de São Paulo, Faculdade de Filosofia, Ciências e Letras de Ribeirão Preto. Endereço para correspondência: Faculdade de Filosofia, Ciências e Letras USP; Núcleo de Ensino e Pesquisa em Psicologia Clínica; Av. Bandeirantes, 3900; Ribeirão Preto, SP; CEP: 14040-901.E-mail: rodrigosanchesperes@yahoo.com.br

José Sterza Justo, doutor em Psicologia Social pela Pontifícia Universidade Católica de São Paulo, é professor no Departamento de Psicologia Social, Evolutiva e Escolar da Universidade Estadual Paulista, Faculdade de Ciências e Letras de Assis. E-mail: justo@assis.unesp.br 